\title{
Disparities in caesarean section prevalence and determinants across sub-Saharan Africa countries
}

\author{
Sanni Yaya ${ }^{1 *} \mathbb{D}$, Olalekan A. Uthman², Agbessi Amouzou ${ }^{3}$ and Ghose Bishwajit ${ }^{1}$
}

\begin{abstract}
Background: Access to safe Cesarean section (C-section) in resource-constrained settings such as sub-Sahara Africa (SSA) region is a foremost approach to reduce maternal mortality. C-section is an obstetric operative procedure used appropriately to improve delivery outcomes. However, errors in the procedure have enormous potential harm that may outweigh the benefits. This study assessed the prevalence and determinants of C-section in several SSA countries. This study examined the prevalence and determinants associated with cesarean delivery in SSA countries.

Methods: Secondary data of women of reproductive age (15-49 years) from the current Demographic and Health Survey (DHS) in 34 SSA countries was utilized in this study. The mode of delivery among women was the primary outcome variable. Percentage and descriptive statistics were used to conduct univariate analyses. Furthermore, multivariable multilevel logistic regression was used to investigate correlates of C-section among SSA women.

Results: Results showed disparities in the percentage of C-section among women from 34 SSA countries. C-section at public healthcare settings ranged from 3\% in Burkina Faso to 15.6\% in Ghana. However, in private healthcare settings, C-section ranged from 0\% in Sao Tome and Principe to 64.2\% in Rwanda. Overall, C-section was 7.9\% from public healthcare and $12.3 \%$ from private healthcare facilities respectively. In the adjusted regression model; women aged 35-49 had increase in the odds of C-section, while a unit increase in the number of children ever born had 17 and 20\% significant reduction in the odds of C-section in public and private healthcare respectively. Assessing public healthcare settings; women from richer/richest households, male and large size children at birth had increase in the odds of C-section, while those from rich neighbourhood had reduction in the odds of C-section. In private healthcare settings, women with high decision making power and multiple births had increase in the odds of C-section, while those who attended ANC visits had significant reduction in the odds of C-section.

Conclusion: The findings from this study would help formulate health policies and implement actions that would improve the outcome of C-section care. Monitoring of emergency obstetric care services is necessary to address issues connected to poor C-section outcomes in resource-constrained settings. Also training of medical personnel including midwives and nurses in emergency obstetric care, ensuring accessibility to life-saving drugs and supplies should be encouraged in health care system.
\end{abstract}

Keywords: Cesarean section, Delivery, Sub-Saharan Africa, Vaginal birth, Maternal health, Global health

\footnotetext{
* Correspondence: brammaputram@gmail.com

${ }^{1}$ School of International Development and Global Studies, University of

Ottawa, Ottawa, ON K1N 6N5, Canada

Full list of author information is available at the end of the article
}

(c) The Author(s). 2018 Open Access This article is distributed under the terms of the Creative Commons Attribution 4.0 International License (http://creativecommons.org/licenses/by/4.0/), which permits unrestricted use, distribution, and reproduction in any medium, provided you give appropriate credit to the original author(s) and the source, provide a link to the Creative Commons license, and indicate if changes were made. The Creative Commons Public Domain Dedication waiver (http://creativecommons.org/publicdomain/zero/1.0/) applies to the data made available in this article, unless otherwise stated. 


\section{Background}

By the end of year 2015, the Sustainable Development Goals (SDGs) emerged with a target to bring a reduction in maternal mortality ratio (MMR) to less than 70 per 100,000 live births worldwide, and to ensure healthy lives for all at all ages by 2030 [1]. Despite the immense global interventions to reduce the problem of mother and child deaths due to complications in pregnancy and delivery, the magnitude of maternal mortality remains unabated specifically in sub-Sahara Africa region [2]. This implies the necessity to provide evidence-based, quality and high-impact maternal healthcare services, particularly; universal access to emergency gynecological and obstetric care be made a priority on the global health agenda. Predominantly, developing countries are known to account for approximately $99 \%$ of the estimated 303,000 maternal deaths that occur per year worldwide, where access to antenatal care, family planning, postnatal care and emergency obstetric services have been reported inadequate [3].

In the quest to achieve SDG-3, equity and equality in availability to emergency obstetric care including assisted vaginal delivery together with safe caesarean section (C-section) is exceedingly essential [4]. C-section is a known life-saving procedure for both mother and child. Contemporary obstetrics and gynecological practice for medical, economic and social reasons have observed higher rate of cesarean section universally $[5,6]$. There is an increasing attention that $\mathrm{C}$-section rates have consistently been on the rise, regardless of race, age, medical condition and gestational age. Global attention over such upsurge have persuaded World Health Organization (WHO) to recommend that C-section prevalence should not surpass $15 \%$ [7], with numerous evidence signifying that $\mathrm{C}$-section prevalence beyond $15 \%$ were not linked to further reduction in maternal and child morbidity and mortality [8]. Notwithstanding, there are disparities in the prevalence of $\mathrm{C}$-section in developing countries ranging between 2 and $39 \%[5,9]$.

C-section has become a prominent indicator of accessing progress in emergency obstetric care, and a method to avert complications during labour and delivery [10]. The role of caesarean section in poor-resource settings is difficult to obviously describe. In many low- and middle-income countries, the tool has been reportedly underutilized especially among the disadvantaged populations, and overemployed by the privileged group, while no consideration has been adopted to ensure that universal access is obtained [11]. $\mathrm{C}$-section has become a priority in agenda setting to curb the menace of maternal death through improved quality and use of services for the management and treatment of complications in pregnancy, labor and delivery [7]. Holistically, a foremost strategy in the reduction of maternal morbidity and mortality includes promoting skilled birth attendance or institutional delivery and utilization of prompt C-section as a remedy to salvage delivery crisis [12]. Evidence-based studies have shown numerous factors connected to consistent rise in the rate of $\mathrm{C}$-section in many communities. As reported in a previous study, women with higher economic class underwent more C-section than women without formal education and those in low wealth index class. Furthermore, women who delivered in private health facilities are known to have more $\mathrm{C}$-section than the women who utilized government owned health facilities [13].

Disparities exist in C-section trends across diverse populations, economic class amongst other factors in sub-Saharan Africa region and the world at large [14]. Elsewhere in sub-Sahara Africa, a study showed huge inequalities in $\mathrm{C}$-section levels across diverse socio-environmental and demographic factors indicating differentials in accessibility to health care services [15]. More so, population based studies involving large number of women who delivered at referral centers in sub-Sahara Africa countries, identified individual woman factors related to $\mathrm{C}$-section, while variations were noted across the rate of intrapartum, emergent and elective $\mathrm{C}$-sections [16]. Considering the various types of $\mathrm{C}$-section, prominent maternal risk factors are history of previous C-section, hypertension, premature rupture of membranes amongst others [16].

As a major abdominal surgery, C-section commonly happens under critical conditions as signified during fetal distress, hemorrhage, cephalopelvic disproportion and eclampsia. Unfortunately, this procedure is sometimes performed by incompetent and poorly trained personnel [11]. Despite it is being performed in overall high-risk women with baseline risk of adverse outcomes, $\mathrm{C}$-section can worsen the outcomes through damage to pelvic organs, increased blood loss and increased risk of thromboembolism, to name but a few [11]. However, $\mathrm{C}$-section can prevent stillbirth, maternal morbidity and complications-related mortality during pregnancy and childbirth. It is in the light of the above that this study examines the prevalence and correlates of caesarean section in sub-Sahara Africa region.

\section{Methods}

\section{Data source}

Secondary data analysis was conducted involving individual woman component of the dataset from the Demographic and Health Survey (DHS). Women from thirty-four (34) countries were included from SSA region where data had previously been collected 2008-2016. The selected countries were; Southern SSA countries (Lesotho, Namibia and Zimbabwe), Eastern SSA countries (Burundi, Comoros, Ethiopia, Kenya, Madagascar, Malawi, Mozambique, Rwanda, Tanzania, Uganda and Zambia), Western SSA 
countries (Benin, Burkina-Faso, Cameroon, Chad, Cote d'Ivoire, Gambia, Ghana, Guinea, Liberia, Mali, Niger, Nigeria, Sao Tome \& Principe, Senegal, Sierra Leone and Togo) and Central SSA countries (Angola, Congo, Gabon and Democratic Republic of Congo), see the details of the sample size from Table 1 . The data is publicly available and can be accessed from MEASURE DHS database at http://dhsprogram.com/data/available-datasets.cfm. DHS are usually implemented by the National Population
Commission (NPC) with financial and technical assistance by ICF International provisioned through the USAIDfunded MEASURE DHS program. DHS are nationally representative surveys that collect information on a wide range of topics such as demographic, socioeconomic, family planning and domestic violence amongst other areas. The survey covered men and women aged between 15 and 49 years, under- 5 children residing in non-institutional settings and households. It involved multi-stage stratified

Table 1 Description of Demographic and Health Surveys data by countries, in sub-Saharan Africa, 2007 to 2016

\begin{tabular}{|c|c|c|c|c|c|}
\hline \multirow[b]{2}{*}{ Country } & \multirow[b]{2}{*}{ Year } & \multirow[b]{2}{*}{ Number of births } & \multirow[b]{2}{*}{ Neighbourhood } & \multicolumn{2}{|l|}{$\mathrm{HDI}$} \\
\hline & & & & Value & Category \\
\hline Angola & 2016 & 4087 & 537 & 0.533 & High HDI \\
\hline Benin & 2012 & 7913 & 748 & 0.485 & Moderate HD \\
\hline Burkina Faso & 2010 & 7636 & 561 & 0.402 & Low HDI \\
\hline Burundi & 2010 & 3197 & 375 & 0.404 & Low HDI \\
\hline Cameron & 2011 & 5032 & 562 & 0.518 & Moderate HD \\
\hline Chad & 2014 & 2273 & 438 & 0.396 & Low HDI \\
\hline Comoros & 2012 & 1575 & 252 & 0.727 & High HDI \\
\hline Congo & 2011 & 5579 & 383 & 0.592 & High HDI \\
\hline Cote d'Ivoire & 2012 & 3106 & 346 & 0.435 & Low HDI \\
\hline DR Congo & 2013 & 8463 & 530 & 0.474 & Moderate HD \\
\hline Ethiopia & 2008 & 2699 & 548 & 0.448 & Low HDI \\
\hline Gabon & 2012 & 3488 & 333 & 0.697 & High HDI \\
\hline Gambia & 2013 & 3233 & 281 & 0.452 & Low HDI \\
\hline Ghana & 2014 & 3091 & 422 & 0.579 & High HDI \\
\hline Guinea & 2012 & 2029 & 276 & 0.414 & Low HDI \\
\hline Kenya & 2014 & 8738 & 1504 & 0.555 & High HDI \\
\hline Lesotho & 2014 & 1986 & 395 & 0.497 & Moderate HD \\
\hline Liberia & 2013 & 2987 & 319 & 0.427 & Low HDI \\
\hline Malawi & 2016 & 12,478 & 850 & 0.476 & Moderate HD \\
\hline Mali & 2012 & 3947 & 390 & 0.442 & Low HDI \\
\hline Mozambique & 2011 & 4962 & 591 & 0.418 & Low HDI \\
\hline Namibia & 2013 & 3454 & 532 & 0.64 & High HDI \\
\hline Niger & 2012 & 2990 & 404 & 0.353 & Low HDI \\
\hline Nigeria & 2013 & 7591 & 818 & 0.527 & High HDI \\
\hline Rwanda & 2014 & 5429 & 492 & 0.498 & Moderate HD \\
\hline Senegal & 2011 & 5367 & 390 & 0.494 & Moderate HD \\
\hline Sierra Leone & 2013 & 4966 & 429 & 0.42 & Low HDI \\
\hline Tanzania & 2015 & 4634 & 600 & 0.531 & High HDI \\
\hline Togo & 2014 & 3549 & 330 & 0.487 & Moderate HD \\
\hline Uganda & 2016 & 7747 & 696 & 0.493 & Moderate HD \\
\hline Zambia & 2013 & 6768 & 717 & 0.579 & High HDI \\
\hline Zimbabwe & 2015 & 3973 & 399 & 0.516 & Moderate HD \\
\hline Madagascar & 2009 & 3241 & 546 & 0.512 & Moderate HD \\
\hline Sao Tome \& Principe & 2008 & 1119 & 104 & 0.574 & High HDI \\
\hline
\end{tabular}


cluster design based on a list of enumeration areas (EAs), which are systematically selected units from localities and constitute the Local Government Areas (LGAs). The LGAs are subdivisions of each of the administrative States (including the Federal Capital Territory) and classified under geographical zones/divisions [17].

\section{Variable measurement \\ Outcome variable}

The dependent variable was the mode of delivery among women of reproductive age. Data about the method of last pregnancy delivery was collected in dichotomous form as either caesarean section or otherwise.

\section{Independent variables}

The explanatory factors include; current age of a respondent (15-19, 20-24, 25-29, 30-34, 35-39, 40-44, 45-49 years), place of residence (urban vs rural), respondent and partner's educational attainment (none, primary, secondary and higher), religion (Christianity, Islam, traditional and other religion), sex of household head (male vs female), frequency of reading newspaper, frequency of listening to radio, frequency of watching television, birth type (singleton vs multiple), sex of child (male vs female), total children ever born, age of respondents at first birth, number of antenatal visits, size of child at birth (very large, larger than average, average, smaller than average, very small) and employment status (employed vs unemployed), women's decision making power; was evaluated with questions on who made decisions about women's own health care, household purchases, visits to family members and husband earnings. All decision components were categorized into a decision made by husband or other person, a decision made together with the woman, or a decision made by the woman only. In addition, on wealth index; the calculation of household socioeconomic level involved the use of items such as possession of TV, radio, bicycle, type of floor, roof, toilet facility, water source and so forth. The principal component analysis (PCA) was used in assigning a score which were then summed and standardized for the households. The standardized scores places the households on a continuous scale based on relative wealth scores. The scores were thus categorized into quintiles to rank the household as poorest/poorer/middle/ richer/richest. The place of delivery was grouped as private vs public health facility.

Neighbourhood-level factor was operationalized with a principal component analysis using the proportion of respondents with: no formal education, rural resident, unemployed and living below the poverty level (asset index below $20 \%$ poorest quintile). A standardized score with mean 0 and standard deviation 1 was computed from this index; with higher scores indicative of lower socio-economic position (SEP). We grouped the scores into tertiles to allow for nonlinear effects and provide results that were more readily interpretable in the policy arena.

Country-level factor included human development index, a measure of country's intensity of deprivation, which is the average percentage of deprivation experienced by people in multidimensional poverty. The country-level variables were also grouped into tertiles (low, middle and high levels).

\section{Ethical approval}

We conducted the analyses using publicly available data from demographic health surveys. Prior to each interview, participants gave informed consent to participate in the survey. DHS Program is consistent with the standards for ensuring the protection of respondents' privacy. ICF International ensures that the survey complies with the U.S. Department of Health and Human Services regulations for the respect of human subjects. No further approval was required for this study since the data is secondary and is available in the public domain. More details about data and ethical standards are available at: http:// goo.gl/ny8T6X.

\section{Data management plan}

The baseline socio-economic, demographic and other characteristics of respondents were computed using summary statistics together with percentages. The complex survey module (svyset) was used to account for sample weight. In addition, the association between explanatory variables and $\mathrm{C}$-section among women was investigated using multivariable multilevel fixed-and-random effect logistic regression was used to obtain stratified models for public and private health facilities. The results of fixed effects (measures of association) were reported as odds ratios (ORs) with their 95\% credible intervals (CrIs). Significance level was set at 5\%. Data analyses was done using STATA version 14.0 (Statacorp, College Station, Texas, United States of America).

\section{Results \\ Sample characteristics}

We analysed information on 159,327 respondents from 32 countries in sub-Saharan Africa (Table 1). Table 1 shows the countries, year of data collection, and the surveys characteristics. The median number of neighbourhoods sampled was 434, ranging from 104 in Sao Tome \& Principe to 1504 in Kenya. The median number of respondents was 3960 (range: 1119 to 12,478). As shown in Fig. 1, there was a wide variation in the percentage of C-Section. The characteristics of the pooled sample is shown in Table 2. 


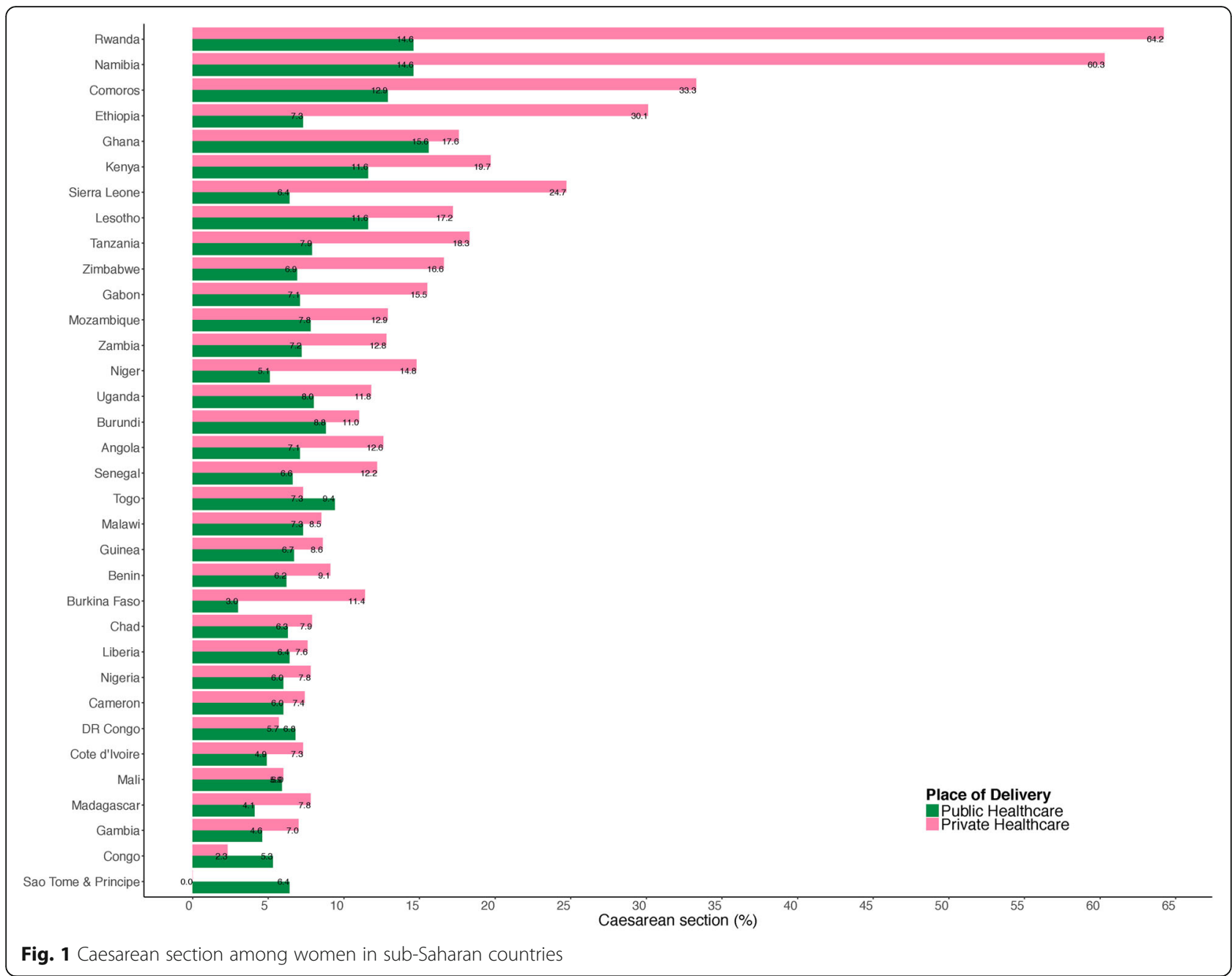

\section{C-section at public healthcare settings}

The prevalence of c-section ranged from 3\% in Burkina Faso to $15.6 \%$ in Ghana (Fig. 1). The results of multilevel model is shown in Table 3. In the fully adjusted model controlling for the effects of individual, neighbourhood and country level factors, maternal age, wealth, sex of child, number of children and size of the baby at birth were significantly associated with odds of c-section. Women aged 35 to 49 years old were more likely to have had c-Section to those aged 15 to 24 years old $(\mathrm{OR}=2.75$, $95 \%$ CrI 2.33to 3.22). Women from the richest households were almost as twice as likely to have had c-Section than those from poorest households $(\mathrm{OR}=1.97,95 \% \mathrm{CrI} 1.54$ to 2.55). Male children were more likely to have been delivered via $\mathrm{c}$-section than female children $(\mathrm{OR}=1.21$, 95\% CrI 1.10 to 1.33 . The odds of c-section decreased with increasing number of children ever born $(\mathrm{OR}=0.83,95 \%$ CrI 0.81 to 0.86 ). Children large size at birth were more likely to have been delivered via c-section $(\mathrm{OR}=1.15$, 95\% CrI 1.05 to 1.26 ).

\section{C-section at private healthcare settings}

The results of multilevel model is shown in Table 3. In the fully adjusted model controlling for the effects of individual, neighbourhood and country level factors, maternal age, decision making power, multiple birth and number of children were significantly associated with odds of c-section. Women aged 35 to 49 years old were more likely to have had c-Section to those aged 15 to 24 years old $(\mathrm{OR}=4.31,95 \% \mathrm{CrI} 2.83$ to 6.67$)$. Women with high decision making power were more likely to have had c-section $(\mathrm{OR}=1.52,95 \% \mathrm{CrI} 1.14$ to 1.97$)$. The odds of c-section decreased with increasing number of children ever born (OR $=0.80,95 \%$ CrI 0.75 to 0.86 ).

\section{Percentage of caesarean section among women in sub-Sahara Africa countries}

Figure 1 presents the percentage of $\mathrm{C}$-section among women from 34 SSA countries. The highest percentage (64.2\%) of C-section was reported among deliveries in Rwanda, while Namibia reported about $60.3 \%$, Comoros 
Table 2 Summary of pooled sample characteristics of the Demographic and Health Surveys data in sub-Saharan Africa

\begin{tabular}{llll}
\hline Caesarean section & & \\
\hline & Overall (\%) & $\begin{array}{l}\text { Public } \\
\text { healthcare (\%) }\end{array}$ & $\begin{array}{l}\text { Private } \\
\text { healthcare (\%) }\end{array}$ \\
& 159,327 & 139,882 & 19,445 \\
\hline CS & & 7.9 & 12.3
\end{tabular}

Age (\%)

$15-24$
$25-34$
$35-49$

Wealth (\%)

Poorest

Poorer

$14.5 \quad 5.1$

Middle

Richer

Richest

Maternal's education (\%)

No education

Primary

Secondary+

Paternal's education (\%)

No education

Primary

Secondary+

Religion

Christianity
Islam

Others

Media access

0

$$
1
$$$$
2
$$$$
3
$$

Household head

\section{Female}

Male

Currently working

Yes

No

Decision making power

$$
\text { Low }
$$

High

Sex of child

Male
Female

$\begin{array}{lll}31.5 & 7.1 & 9.1 \\ 46.4 & 8.0 & 12.8 \\ 22.1 & 8.7 & 15.3\end{array}$

$17.5 \quad 5.8$

19.7

23.0

25.3

6.6

6.9

7.5

8.2

9.8

17.6

$27.5 \quad 5.3$

$37.0 \quad 7.3$

$35.5 \quad 10.8$

$25.8 \quad 5.1$

$30.1 \quad 6.9$

$44.1 \quad 9.6$

$70.7 \quad 8.5$

$23.9 \quad 6.6$

$5.4 \quad 6.4$

7.7

9.2

15.4

6.7

8.2

13.7

12.9

9.0

7.7

$\begin{array}{lll}23.3 & 5.7 & 6.4\end{array}$

$\begin{array}{lll}31.1 & 6.6 & 8.8\end{array}$

$\begin{array}{lll}30.2 & 8.7 & 11.7\end{array}$

$\begin{array}{lll}15.3 & 12.7 & 20.7\end{array}$

$\begin{array}{lll}77.0 & 9.2 & 12.1\end{array}$

$23.0 \quad 7.5$

12.9

$\begin{array}{lll}37.9 & 7.8 & 12.7\end{array}$

$62.1 \quad 7.9$

12.1

$30.7 \quad 6.6$

8.9

$36.9 \quad 8.8$

12.3

$32.4 \quad 9.7$

15.9

$\begin{array}{lll}48.9 & 8.4 & 11.9\end{array}$

$\begin{array}{lll}51.1 & 7.3 & 12.7\end{array}$
Table 2 Summary of pooled sample characteristics of the

\begin{tabular}{|c|c|c|c|}
\hline \multicolumn{4}{|l|}{ Caesarean section } \\
\hline & Overall (\%) & $\begin{array}{l}\text { Public } \\
\text { healthcare (\%) }\end{array}$ & $\begin{array}{l}\text { Private } \\
\text { healthcare (\%) }\end{array}$ \\
\hline & 159,327 & 139,882 & 19,445 \\
\hline \multicolumn{4}{|l|}{ Multiple birth } \\
\hline No & 99.9 & 7.9 & 12.3 \\
\hline Yes & 0.1 & 12.5 & 25.6 \\
\hline \multicolumn{4}{|l|}{ Large size at birth } \\
\hline Yes & 60.6 & 7.1 & 11.9 \\
\hline No & 39.4 & 8.6 & 11.1 \\
\hline \multicolumn{4}{|l|}{ Antenatal care } \\
\hline None & 4.1 & 6.4 & 10.6 \\
\hline 1 to 4 visits & 49.5 & 7.5 & 10.2 \\
\hline 5 to 8 visits & 33.7 & 8.8 & 13.7 \\
\hline 8 or more visits & 12.7 & 11.5 & 16.0 \\
\hline \multicolumn{4}{|c|}{ Neighbourhood SES (\%) } \\
\hline $\begin{array}{l}\text { Tertile } 1 \text { (least } \\
\text { disadvantaged) }\end{array}$ & 38.8 & 10.9 & 14.6 \\
\hline Tertile 2 & 36.3 & 7.3 & 9.9 \\
\hline $\begin{array}{l}\text { Tertile } 3 \text { (most } \\
\text { disadvantaged) }\end{array}$ & 24.9 & 4.6 & 7.1 \\
\hline \multicolumn{4}{|c|}{ Human Development Index (\%) } \\
\hline Low HDI & 27.1 & 5.5 & 9.7 \\
\hline Moderate HDI & 41.2 & 8.1 & 10.1 \\
\hline High HDI & 31.7 & 9.7 & 15.6 \\
\hline
\end{tabular}
Demographic and Health Surveys data in sub-Saharan Africa (Continued)

and Ethiopia reported 33.3 and $30.1 \%$ respectively from private settings. Overall, public healthcare settings reported lower C-section in several SSA countries including Sao Tome \& Principe (0\%), Congo (2.3\%), Burkina-Faso (3\%) amongst others (see fig. 1 for details).

\section{Discussion}

The focus of this study was to investigate the prevalence and determinants of C-section mode of delivery in SSA countries using current nationally representative data from DHS conducted between 2008 and 2016. The findings from our analysis revealed disparities in the prevalence of C-section across various countries, while some reported substantial increase during the study period, some countries had very low percentage of $\mathrm{C}$-section. The prevalences obtained were similar to previous reports from developing countries [18-20]. According to WHO, the prevalence of $\mathrm{C}$-section in any population should be within the interval of 5-15\%, however, some countries in SSA were found to have below the minimum $5 \%$ recommended by public and private healthcare facilities. Studies have shown that the 
Table 3 Individual compositional and contextual factors associated with Caesarean section in sub-Saharan Africa identified by multivariable multilevel logistic regression models, Demographic and Health Surveys data

\begin{tabular}{lll}
\hline & Place of Delivery & \\
\cline { 2 - 3 } & Public healthcare & Private healthcare \\
$(\mathrm{OR}, 95 \% \mathrm{Crl})$ & $(\mathrm{OR}, 95 \% \mathrm{Crl})$
\end{tabular}

\begin{tabular}{l}
\hline Age (\%) \\
$15-24$ \\
$25-34$ \\
$35-49$ \\
Wealth (\%) \\
Poorest \\
Poorer \\
Middle \\
Richer \\
Richest \\
Maternal's education (\%) \\
No education \\
Primary \\
Secondary+ \\
Paternal's education (\%) \\
No education \\
Primary \\
Secondary+ \\
Religion \\
Christianity \\
Islam \\
Others
\end{tabular}

Media access

Female Household head

Currently working

Decision making power

Low
Medium
High

Sex of child (male vs female)

Multiple birth

Number of children

Large size at birth

Antenatal care

None
1 to 4 visits
5 to 8 visits
8 or more visits
Neighbourhood SES (\%)
Tertile 1 (least disadvantaged)
Tertile 2
Tertile 3 (most disadvantaged)

Tertile 3 (most disadvantaged)

$\begin{array}{ll}1 \text { (reference) } & 1 \text { (reference) } \\ 1.50(1.31 \text { to } 1.72) & 2.32 \text { (1.58 to } 3.47) \\ 2.75 \text { (2.33 to } 3.22) & 4.31 \text { (2.83 to } 6.67)\end{array}$

1 (reference) 1 (reference)

1.07 (0.87 to 1.33 ) $\quad 1.75$ (0.78 to 3.69 )

1.14 (0.91 to 1.44$) \quad 1.24$ (0.53 to 2.68 )

1.34 (1.09 to 1.70$) \quad 1.48$ (0.65 to 3.21$)$

1.97 (1.54 to 2.55$) \quad 2.08$ (0.89 to 4.19$)$

1 (reference) 1 (reference)

1.03 (0.89 to 1.18 ) $\quad 1.15$ (0.71 to 1.79 )

1.09 (0.92 to 1.27 ) $\quad 1.61$ (0.96 to 2.43 )

1 (reference) 1 (reference)

1.04 (0.89 to 1.22$) \quad 0.86$ (0.47 to 1.46$)$

1.13 (0.95 to 1.32$) \quad 1.22$ (0.68 to 2.01 )

1 (reference) 1 (reference)

1.08 (0.94 to 1.25$) \quad 0.54$ (0.37 to 0.75$)$

1.00 (0.78 to 1.23$) \quad 0.62$ (0.30 to 1.08 )

1.02 (0.96 to 1.09$) \quad 1.08$ (0.95 to 1.23 )

1.01 (0.89 to 1.13) 0.94 (0.71 to 1.19 )

0.92 (0.76 to 1.07$) \quad 1.02$ (0.63 to 1.75 )

1 (reference) 1 (reference)

1.05 (0.93 to 1.18 ) $\quad 1.20$ (0.91 to 1.57 )

1.21 (1.10 to 1.33$) \quad 1.03$ (0.85 to 1.23 )

1.01 (0.09 to 3.24) 22.94 (4.24 to 77.55$)$

0.83 (0.81 to 0.86 ) $\quad 0.80$ (0.75 to 0.86 )

1.15 (1.05 to 1.26$) \quad 1.05$ (0.86 to 1.27 )

1 (reference) 1 (reference)

0.86 (0.60 to 1.08 ) $\quad 0.51$ (0.30 to 0.94 )

0.98 (0.68 to 1.24$) \quad 0.60$ (0.35 to 1.12$)$

1.28 (0.90 to 1.66$) \quad 0.84$ (0.48 to 1.65$)$

1 (reference) 1 (reference)

0.86 (0.77 to 0.98$) \quad 1.00$ (0.76 to 1.28$)$

0.79 (0.67 to 0.64$) \quad 1.04$ (0.55 to 1.74$)$
$1.06(0.93$ to 1.20$) \quad 1.52(1.14$ to 1.97$)$
Table 3 Individual compositional and contextual factors associated with Caesarean section in sub-Saharan Africa identified by multivariable multilevel logistic regression models, Demographic and Health Surveys data (Continued)

\begin{tabular}{lll}
\hline & \multicolumn{1}{c}{ Place of Delivery } & \\
\cline { 2 - 3 } & $\begin{array}{l}\text { Public healthcare } \\
\text { (OR, 95\% Crl) }\end{array}$ & $\begin{array}{l}\text { Private healthcare } \\
\text { (OR, 95\% Crl) }\end{array}$ \\
\hline $\begin{array}{l}\text { Human Development Index (\%) } \\
\text { Low HDI }\end{array}$ & 1 (reference) & 1 (reference) \\
Moderate HDI & $1.26(0.91$ to 1.69$)$ & $0.94(0.36$ to 1.75$)$ \\
High HDI & $1.26(0.84$ to 1.70$)$ & $1.09(0.48$ to 2.05$)$ \\
$\begin{array}{l}\text { Random-effect } \\
\text { Country-level } \\
\text { Variance }(95 \% \mathrm{Crl})\end{array}$ & $0.18(0.10$ to 0.31$)$ & $0.46(0.21$ to 0.89$)$ \\
Neighbourhood-level & & \\
$\quad$ Variance $(95 \% \mathrm{Crl})$ & $0.00(0.00$ to 0.00$)$ & $0.00(0.00$ to 0.00$)$ \\
\hline
\end{tabular}

OR Odds ratio, $\mathrm{Crl}$ Credible interval, MOR Median odds ratio, VPC Variance partition coefficient, DIC Bayesian Deviance Information Criteria

prominent reasons for the low coverage of C-sections were insufficient provision of equipment and medicines in the available emergency obstetric health units, lack of skilled birth attendants, unavailability of life-saving obstetrics services, long distances and poor landscapes without proper transportation could cause major geographic barrier in access to emergency obstetric care [21, 22] . Conversely, despite the reasons for the high prevalence in some countries are not completely known due to multifactorial nature, it could be connected to supply-side and demand-side factors. Maternal factors, such as education and other characteristics driven by health professionals, health care system, awareness, perception and socioeconomic factors could be responsible.

The multilevel logistic regression model used to examine significant predictors of $\mathrm{C}$-section, indicated that age, wealth index, parity (number of children ever born), sex of child, size of child at birth, neighbourhood socioeconomic status, women's decision making power, multiple births (i.e: twins, triplets etc.) and antenatal care visits were significantly associated with having a $\mathrm{C}$-section model of delivery. Consistent with previous studies [23, 24], our findings showed that women who belong to the poorest households had lower odds of C-section than those from rich households in SSA countries. The current data have confirmed poverty as a major factor responsible for the low utilization of C-section among women. The cost implication of assessing a crucial life-saving procedure such as C-section is a major factor that could hinder the process of achieving equality health care services utilization as evident in this study. However, women from least disadvantaged neighbourhood had significant reduction in the odds of C-section. Affordability of adequate antenatal care visits; a medium of behavioural change communication through feeding habits, 
exercising and warning signs at onset of pregnancy-related complications enlightenment could help reduce the occurrence on emergency C-section. In this study, older women had higher C-section, which could be due to complications resulting from advanced reproductive age or due to life time C-section data used for this study. This is consistent with the findings from previous study [25].

Further, women with large number of children had less of C-section; the experience from several child births could reduce the risk of pregnancy related and intrapartum complications among the multiparous women. Child factors associated with $\mathrm{C}$-section were sex, size of baby at birth and type of birth. Multiple births such as twins, triplets or more and large baby size or weight could cause cephalo pelvic disproportion or malposition. Child sex was also significantly associated with $\mathrm{C}$-section among women in SSA countries. Previous studies have reported similar factors significantly associated with C-section $[6,26]$.

\section{Strength and limitation}

This study used large sample size involving multiple nationally representative datasets from several countries in SSA to investigate prevalence and correlates of C-section in sub-Sahara Africa region. Nonetheless, the data lacks information relating to clinical indications for $\mathrm{C}$-sections; as the data did not distinguish between elective and emergency C-sections. Also, the use of this information for decisionmaking and comparison should consider the cross-sectional nature of the data which is inadequate to sufficiently establish causality. Maternal empowerment has been known to affect several health care services. In this study, women's decision making power was significantly associated with increased C-section. In an effort to educate women about their birthing rights and options, guides are provided for women on healthy birth mode [27]. Educating expectant mothers with information on pregnancy, delivery and hospital C-section rates could assist women in making informed choices, leading to increase in C-section.

\section{Conclusion}

In practice, healthcare system is grouped into public and private hospitals with specific features according to the country. The differences in $\mathrm{C}$-section prevalence between public and private healthcare settings are either due to the difference in prenatal and delivery care between these two settings that could influence the delivery outcome or the preference of patient mode of delivery. The high prevalence of $\mathrm{C}$-section in private healthcare settings is a broad concept connected with several factors. Therefore, the interventions and programs should be targeted to address both maternal preference and professional attitude towards the mode of delivery. Educational interventions to improve quality of painless labour and vaginal delivery should be introduced in both public and private healthcare settings to lower potential C-section (elective) rate. Women's awareness towards social beliefs as C-section (elective) is safer than normal (vaginal) delivery and information regarding complications of $\mathrm{C}$-section and their outcomes should be enhanced. Active involvement of the policy sector is needed to strengthen equity and universal health coverage in maternal healthcare. The results suggest the need for accurate and timely screening of women during obstetric care and, the choice of performing C-section should be based on clear and well-supported justifications.

\begin{abstract}
Abbreviations
ANC: Antenatal care; C-Section: Cesarean Section; DHS: Demographic Health Survey; IRB: Institutional Review Board; MMR: Maternal mortality ratio;

SDGs: Sustainable Development Goals; SSA: Sub-Saharan Africa; WHO: World Health Organization
\end{abstract}

\section{Acknowledgments}

The authors thank the MEASURE DHS project for their support and for free access to the original data.

Funding

The authors have no support or funding to report.

Availability of data and materials

Data for this study were sourced from Demographic and Health surveys (DHS) and available here: http://dhsprogram.com/data/available-datasets.cfm.

\section{Authors' contributions}

SY contributed to the study design, the review of literature, and analysis of literature, manuscript conceptualisation and preparation. OU, AA and GB critically reviewed the manuscript for its intellectual content and contributed to data analysis as well. SY had final responsibility to submit for publication. All authors read and approved the final manuscript.

\section{Ethics approval and consent to participate}

Ethics approval for this study was not required since the data is secondary and is available in the public domain. More details regarding DHS data and ethical standards are available at: http://goo.gl/hy8T6X.

\section{Consent for publication}

No consent to publish was needed for this study as we did not use any details, images or videos related to individual participants. In addition data used is available in the public domain.

\section{Competing interests}

The authors declare that they have no competing interests.

\section{Author details}

${ }^{1}$ School of International Development and Global Studies, University of Ottawa, Ottawa, ON K1N 6N5, Canada. ${ }^{2}$ Warwick Centre for Applied Health Research and Delivery (WCAHRD), Division of Health Sciences, Warwick Medical School, University of Warwick, Coventry CV4 7AL, UK. ${ }^{3}$ Bloomberg School of Public Health, Johns Hopkins University, Baltimore, MD 21205, USA.

Received: 14 February 2018 Accepted: 24 May 2018

Published online: 02 July 2018

\section{References}

1. UN General Assembly, Transforming our world: the 2030 Agenda for Sustainable Development, 21 October 2015, A/RES/70/1. Available at: http:// www.refworld.org/docid/57b6e3e44.html. Accessed 3 Mar 2018.

2. Yaya $\mathrm{S}$, Bishwajit $\mathrm{G}$, Shah V. Wealth, education and urban-rural inequality and maternal healthcare service usage in Malawi. BMJ Global Health. 2016;1: e000085. https://doi.org/10.1136/ bmjgh-2016-000085.

3. WHO. Trends in Maternal Mortality: 1990 to 2008. Geneva: World Health Organization; 2010. 
4. Chu K, Cortier H, Maldonado F, Mashant T, Ford N. Cesarean section rates and indications in sub-Saharan Africa: a multi-country study from Medecins sans Frontieres. PLoS One. 2012;7(9):e44484. https://doi.org/10.1371/journal. pone.0044484

5. Lauer JA, Betrán AP, Merialdi M, Wojdyla D. Rates of caesarean section: analysis of global, regional and national estimates. Paediatr Perinatal Epidemiol. 2007;28:98-113.

6. Abebe FE, Gebeyehu AW, Kidane AN, Eyassu GA. Factors leading to cesarean section delivery at Felegehiwot referral hospital, Northwest Ethiopia: a retrospective record review. Reprod Health. 2016;13(6):1-8.

7. WHO. Monitoring Emergency Obstetric Care: A Handbook. Geneva, Switzerland; 2009 .

8. Adnan A, Abu O, Suleiman H, Abu A. Frequency Rate and Indications of Cesarean Sections at Prince Zaid Bin Al Hussein Hospital - Jordan. J Med SciClin Res. 2012;19((1)):82-6.

9. Shamshad B. Factors leading to increased cesarean section rate. Gomal J Med Sci. 2008:6:1.

10. Miller S, Abalos E, Chamillard M, Ciapponi A, Colaci D, Comande AD. Beyond too little, too late and too much, too soon: a pathway towards evidence-based, respectful maternity care worldwide. Lancet. 2016;388: 2176-92.

11. Fawcus S, Pattinson RC, Moodley J, Moran NF, Schoon MG, Mhanga RE, Baloyi S, Bekker E, Gebhardt GS. Maternal deaths from bleeding associated with caesarean delivery: a national emergency. SAMJ. 2016;106(5):472-6.

12. Stanton C, Blanc A, Croft T, Choi Y. Skilled care at birth in the developing world: progress to date and strategies for expanding coverage. J Biosoc Sci. 2007;39(1):109-20.

13. Gebremedhin S. Trend and socio-demographic differentials of cesarean section rate in Addis Ababa, Ethiopia: analysis based on Ethiopia demographic and health surveys data. Reprod Health. 2014;11:14.

14. Cavallaro FL, Cresswell JA, Franca GVA, Victora CG, Barros AJD, Ronsmans C. Trends in cesarean delivery by country and wealth quintile: cross-sectional surveys in southern Asia and sub-Saharan Africa. Bull World Health Organ. 2013;91:914-22.

15. Nilsen C, Ostbye T, Daltveit AK, Mmbaga BT, Sandoy IF. Trends in sociodemographicfactors associated with caesarean section at a Tanzanian referral hospital, 2000 to 2013. Int J Equity Health. 2014;13:87.

16. Briand V, Dumont A, Abrahamowicz M, Traore M, Watier L, Fournier P. Individual and institutional determinants of cesarean section in referral hospitals in Senegal and Mali: a cross-sectional epidemiological survey. BMC Pregnancy Childbirth. 2012;12:114.

17. Rutstein SO, Rojas G. Guide to DHS Statistics Demographic and Health Survey's DHS Toolkit of methodology for the MEASURE DHS Phase III project, implemented from 2008-2013: United States Agency for International Development (USAID). MEASURE DHS/ICF International.

18. Mumtaz S, Bahk J, Khang YH. Rising trends and inequalities in cesarean section rates in Pakistan: evidence from Pakistan demographic and health surveys, 1990-2013. PLoS One. 2017;12(10):e0186563. https://doi.org/10. 1371/journal.pone.0186563.

19. Betran AP, Ye J, Moller AB, Zhang J, Gumezoglu AM, Torloni MR. The increasing trend in cesarean section rates: global, regional, and national estimates: 1990-2014. PLoS One. 2016;11:e0148343. https://doi.org/10.1371/ journal.pone.0148343.

20. Neuman M, Alcock G, Azad K, Kuddus A, Osrin D, More NS. Prevalence and determinants of caesarean section in private and public health facilities in underserved south Asian communities: cross-sectional analysis of data from Bangladesh, India and Nepal. BMJ Open. 2014;4:e005982. https://doi.org/10. 1136/bmjopen-2014-005982.

21. Bailey P, Paxton A, Lobis S, Fry D. The availability of life-saving obstetric services in developing countries: an in-depth look at the signal functions for emergency obstetric care. Int J Gynaecol Obstet. 2006;93:285-91. https://doi. org/10.1016/j.ijgo.2006.01.028.

22. Gabrysch S, Cousens S, Cox J, Campbell OM. The influence of distance and level of care on delivery place in rural Zambia: a study of linked national data in a geographic information system. PLoS Med. 2011;8:e1000394. https://doi.org/10.1371/journal.pmed.1000394

23. Anwar I, Nababan HY, Mostari S, Rahman A, Khan JA. Trends and inequities in use of maternal health care services in Bangladesh, 1991-2011. PLoS One. 2015;10:e0120309. https://doi.org/10.1371/journal.pone.0120309.

24. Ronsmans C, Holtz S, Stanton C. Socioeconomic differentials in caesarean rates in developing countries: a retrospective analysis. Lancet. 2006;368:1516-23.
25. Khan MN, Islam MM, Shariff AA, Alam MM, Rahman MM. Socio-demographic predictors and average annual rates of caesarean section in Bangladesh between 2004 and 2014. PLoS One. 2017;12(5):e0177579. https://doi.org/10. 1371/journal.pone.0177579.

26. Vieira GO, Fernandes LG, de Oliveira NF, Silva LR, Vieira TDO. Factors associated with cesarean delivery in public and private hospitals in a city of northeastern Brazil: a cross-sectional study. BMC Pregnancy Childbirth. 2015;15:132.

27. McAllister E. Transparency in maternity care: empowering women to make educated choices. J Perinat Educ. 2008;17(4):8-11.

\section{Ready to submit your research? Choose BMC and benefit from:}

- fast, convenient online submission

- thorough peer review by experienced researchers in your field

- rapid publication on acceptance

- support for research data, including large and complex data types

- gold Open Access which fosters wider collaboration and increased citations

- maximum visibility for your research: over $100 \mathrm{M}$ website views per year

At BMC, research is always in progress.

Learn more biomedcentral.com/submissions 